\title{
Silica-scavenging effect in zirconia electrolytes: assessment of lanthanum silicate formation
}

Received: 21 March 2006 / Revised: 11 May 2006 / Accepted: 11 May 2006 / Published online: 8 June 2006

C) Springer-Verlag 2006

\begin{abstract}
Yttria-stabilized zirconia (YSZ)-based composite electrolytes were produced by mixture and firing of the base electrolyte, namely with silica, and silica and lanthanum oxide, to study the impact of presence and formation of new phases on the electrical performance of the composite materials. Combined information obtained from structural, microstructural, and electrical characterization confirmed the formation of an apatite-type solid solution based on $\mathrm{La}_{9.33} \mathrm{Si}_{6} \mathrm{O}_{26}$. The effectiveness of lanthanum oxide addition to remove silica by reaction was demonstrated. However, the conductivity of the composite electrolytes is lower than that of YSZ, probably due to lanthanum zirconate formation in-between the ceramic grains and/or relatively poor transport properties of the formed lanthanum silicate phase. The adopted procedure can be extended to other systems and combinations of properties based on predictable phase interactions.
\end{abstract}

Keywords Yttria stabilized zirconia $\cdot$ Lanthanum silicate $\cdot$ Composite electrolyte $\cdot$ Scavenging effect $\cdot$ Silica

\section{Introduction}

Oxygen-ion conducting materials are needed for applications like solid oxide fuel cells (SOFCs), sensors, and several other devices. Solid electrolytes with the fluorite structure, namely based on $\mathrm{ZrO}_{2}$ and $\mathrm{CeO}_{2}$, were extensively studied in the past [1-6]. The existing knowledge on the defect structure of these materials provided the basis for transport property design by appropriate doping.

Besides the fluorite-related classical systems, perovskites (LSGM) and perovskite-related structures $\left(\mathrm{K}_{2} \mathrm{NiF}_{4}\right)$,

\footnotetext{
A. V. Kovalevsky · F. M. B. Marques $(\bowtie) \cdot$ V. V. Kharton ·

F. Maxim · J. R. Frade

Ceramics and Glass Engineering Department, CICECO,

University of Aveiro,

3810-193 Aveiro, Portugal

e-mail: fmarques@cv.ua.pt
}

also the so-called BIMEVOX and LAMOX families of materials, and the apatites derived from $\mathrm{La}_{10}\left(\mathrm{SiO}_{4}\right)_{6} \mathrm{O}_{3}$ and Ge-based analogues are a subject of interest for their high ionic conductivity [5-25].

While the search for novel materials with improved conductivity is still a major challenge, technological developments face a variety of other constraints, namely due to the cost of state-of-the-art electrolytes. One special example is yttria-stabilized zirconia (YSZ). High-purity powders that are able to sinter at modest temperatures without sintering aids are quite expensive. Cheap and lower quality powders usually include silica as a minor impurity, but this secondary phase has a major impact on the electrical properties, being responsible for a large grain boundary impedance. This situation is not acceptable for current-carrying devices like SOFCs, due to a dramatic drop in efficiency related to ohmic losses. Furthermore, the tendency to lower operating temperatures of SOFCs clearly prevents the utilization of materials with poor grain boundary performance.

Several years ago, the potential of alumina additions to combine with silica was demonstrated [26]. Silica can be removed from grain boundaries by formation of new phases (e.g., mullite), or simply by preferential wetting of alumina grains. This is known as the scavenger effect. The only drawback of this solution is the insulating character of these new phases, also with a negative influence on the overall performance of these materials.

As already mentioned, in recent years, large attention is being given to a family of materials with the apatite structure. Lanthanum silicates with the apatite structure were found to exhibit high oxygen ion conductivity. $\mathrm{La}_{10-\mathrm{x}}\left(\mathrm{SiO}_{4}\right)_{6} \mathrm{O}_{3-1.5 \mathrm{x}}$ is a key example of this new family of materials. Attempts to change the ionic conductivity of these materials included replacement of $\mathrm{Sr}$ for La, La deficiency, and replacement of $\mathrm{Al}$ or Fe for Si. In general, materials with La deficiency and more than 26 oxygen atoms per formula unit exhibit quite large ionic conductivities [15-25]. Considering the interesting performance of these materials, the potential combination of silica present in some YSZ powders, with formation of apatite-type phases, was exploited in this work. For 
comparison, the combined role of alumina and silica additions was also reviewed.

\section{Experimental description}

The starting (and reference) material in these experiments was pure $8 \mathrm{~mol} \% \mathrm{YSZ}$ (from Tosoh). The remaining compositions were prepared by addition of $\mathrm{SiO}_{2}$, (Merck), $\mathrm{Al}_{2} \mathrm{O}_{3}$ (Alfa Aesar), and $\mathrm{La}_{2} \mathrm{O}_{3}$ (Aldrich). Before weighing, lanthanum oxide and silica were annealed in air at 1,473 and $873 \mathrm{~K}$, respectively. Lanthanum oxide was added in adequate proportions to fully combine with silica and yield apatite $\left(\mathrm{La}_{9.33} \mathrm{Si}_{6} \mathrm{O}_{26}\right)$. The nominal composition of this apatite-type phase (assuming complete reaction between silica and $\mathrm{La}_{2} \mathrm{O}_{3}$ ) was selected to provide minimum $\mathrm{La}_{2} \mathrm{O}_{3}$ activity so as to minimize the tendency for formation of a pyrochlore phase $\left(\mathrm{La}_{2} \mathrm{Zr}_{2} \mathrm{O}_{7}\right)$, a known reaction product from interaction between zirconia and lanthanum oxide or lanthanum-containing materials (e.g., LSM or LSC, Sr-doped lanthanum manganite or cobaltite, commonly used as cathodes for SOFCs [27, 28]). The alumina to silica mole ratio was $2: 1$. No attempt was made to optimize this ratio as this was a secondary activity in the present work. However, lower alumina content would have little potential for combination with silica. High alumina additions prevent grain growth with influence on the microstructural characteristics, desirably similar to the remaining compositions for comparison.

One first set of compositions included additions of $5 \mathrm{~mol} \%$ $\mathrm{SiO}_{2}$, aiming at an easy identification of reaction products (pyrochlore, apatite, or both), although this high silica content is hardly typical of low-grade powders. One second set of compositions, including only $0.5 \mathrm{~mol} \% \mathrm{SiO}_{2}$, tried to reproduce in closer detail a typical impurity level of lowgrade powders. For the sake of simplicity, the different composites will be named as YSZsil (YSZ + silica), YSZapat (YSZ + apatite), and YSZalusil (YSZ + alumina + silica) to emphasize the relevance of dominant phases present in these materials.

The different compositions were processed by a conventional ceramic route including powder milling, pressing, and solid-state reaction at $1,873 \mathrm{~K}$ for $10 \mathrm{~h}$ after heating at a rate of $5 \mathrm{~K} / \mathrm{min}$. In the case of YSZ with addition of both $\mathrm{La}_{2} \mathrm{O}_{3}$ and $\mathrm{SiO}_{2}$, attempts to prepare dense samples, by simple milling of powder mixtures with subsequent pressing and sintering, failed. This was due to combination of lanthanum oxide with water vapor and/or carbon dioxide in the course of processing; the decomposition of lanthanum hydroxide and/or carbonate on heating resulted in cracking of the ceramic samples. These samples were thus prepared using one additional thermal treatment of the oxide powder mixtures, consisting of prereaction and passivation at $1,223 \mathrm{~K}$ for $5 \mathrm{~h}$; then, the powder mixtures were compacted and sintered.

All samples were characterized by scanning electron microscope (SEM)/energy dispersive spectroscopy (EDS), $\mathrm{X}$-ray diffractometry (XRD), and impedance spectroscopy in air to try to identify possible correlations between phase composition, microstructure, and electrical properties. The
XRD patterns were collected at room temperature using a Rigaku D/MAX-B diffractometer $\left(\mathrm{Cu} K_{\alpha}, 2 \theta=10-100^{\circ}\right.$, step $\left.0.02^{\circ}, 1 \mathrm{~s} / \mathrm{step}\right)$. The microstructure was examined using a Hitachi S-4100 SEM with a Rontec UHV Detection System for the EDS. The temperature dependencies of the total conductivity $(\sigma)$ were measured by AC impedance spectroscopy (HP4284A precision LCR meter, $20 \mathrm{~Hz}-$ $1 \mathrm{MHz})$, and the values of the activation energy $\left(E_{\mathrm{a}}\right)$ were calculated by the standard equation:

$\sigma=\left(\sigma_{0} / T\right) \cdot \exp \left(-E_{a} / R T\right)$

where $\sigma_{0}$ is the preexponential factor.

\section{Results and discussions}

$\mathrm{SiO}_{2}$-rich samples

The formation of apatite from reaction between silica and lanthanum oxide was confirmed by XRD, as shown in Fig. 1. However, the XRD data were not enough to demonstrate single formation of the pyrochlore phase due to significant overlap of major peaks of this phase with those of other phases which may present in the composite electrolytes. At the same time, there is also free $\mathrm{SiO}_{2}$ present in the apatite-containing sample. This might indicate that a small amount of lanthanum oxide indeed

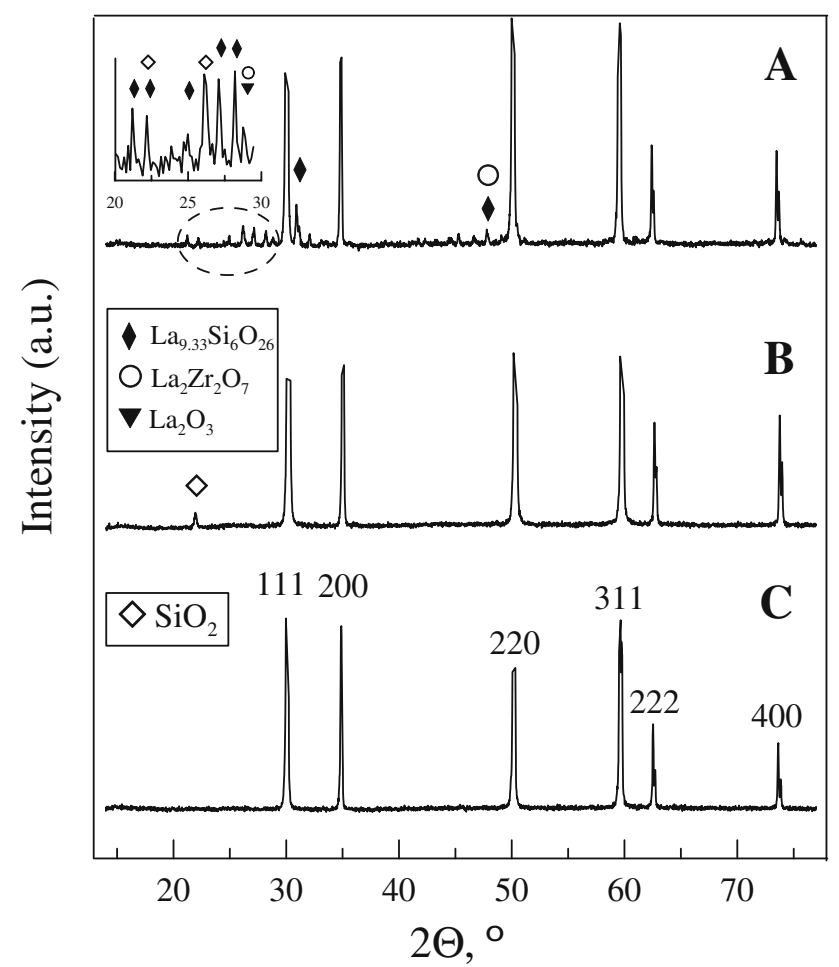

Fig. 1 XRD pattern of fired samples with nominal compositions: a YSZapat; b YSZsil; c YSZ. The identification of the relevant phases is shown in the inset, and the meaning of the short designations can be found in the main text 
reacted with zirconia to form the pyrochlore phase, leaving some free silica.

The lattice parameters of YSZ-derived compositions (Table 1) show negligible changes with nominal composition. In the case of $\mathrm{SiO}_{2}$ additions, the only expected effect would be a loss of yttrium to the silica-based secondary phase due to lixiviation. The impact of such a loss would be a decrease in the YSZ lattice parameter, as large $\mathrm{Y}^{3+}$ cations occupy substitutional positions with respect to the smaller $\mathrm{Zr}^{4+}$ cations. No effect is noticed suggesting negligible loss of the dopant cation. In the case of mixtures with lanthanum oxide, a slight decrease in lattice parameter might suggest some loss of yttrium, but the magnitude of this effect is again quite small.

Microstructures of these samples, in Fig. 2, show rather significant differences. The classical and regular microstructure of pure YSZ (Fig. 2c) shifts to almost isolated YSZ grains surrounded by silica (Fig. 2b) or to a composite material with dispersed grains of apatite (Fig. 2a), as discussed during the analysis of the XRD data. The average grain size of YSZ is roughly preserved irrespective of the phase composition.

The electrical characterization of these samples was able to provide additional information on the likely interaction between precursors during high-temperature processing. Figure 3 shows the impedance results obtained for all samples at $350{ }^{\circ} \mathrm{C}$. The 1 and $10 \mathrm{kHz}$ data points were highlighted as large filled symbols. Pure YSZ shows an almost perfect and complete arc at high frequency, with negligible evidence of the grain boundary contribution, as expected for the high quality of these powders. The small grain boundary contribution is probably masked by the electrode response, as suggested by the change in slope of the low-frequency data in the vicinity of the $1-\mathrm{kHz}$ frequency. In fact, the upper branch of the lower frequency response is clearly related to the electrode process, considering the frequency range involved.

The silica-rich sample shows again one well-defined high-frequency arc (due to bulk effects), almost coincident with the pure YSZ bulk arc. One second well-defined but depressed arc can be found at lower frequencies, in this case related to YSZ-silica interfacial effects, considering the frequency range involved (the high-frequency intercept with the real axis corresponds to a frequency in the order of $10 \mathrm{kHz}$ ). This type of behavior of zirconia-based composites with grains covered by a silica-based phase is coherent with previously reported results on the performance of YSZ-glass composites [29,30].

Table 1 Characteristics of YSZ and YSZ-based composites based on $5 \mathrm{~mol} \% \mathrm{SiO}_{2}$ additions

\begin{tabular}{llll}
\hline $\begin{array}{l}\text { Nominal } \\
\text { composition }\end{array}$ & $\begin{array}{l}\text { Unit cell } \\
\text { parameter } a(\mathrm{~nm})\end{array}$ & $\begin{array}{l}\rho_{\exp } \\
\left(\mathrm{g} / \mathrm{cm}^{3}\right)\end{array}$ & $\begin{array}{l}\text { Activation energy } \\
\text { for total conductivity } \\
\text { in air }(\mathrm{kJ} / \mathrm{mol})\end{array}$ \\
\hline YSZ & 0.51437 & 5.55 & $96 \pm 3(473-1,023 \mathrm{~K})$ \\
YSZsil & 0.51438 & 5.49 & $91 \pm 4(473-1,073 \mathrm{~K})$ \\
YSZapat & 0.51434 & 5.26 & $99 \pm 3(523-1,223 \mathrm{~K})$ \\
\hline
\end{tabular}

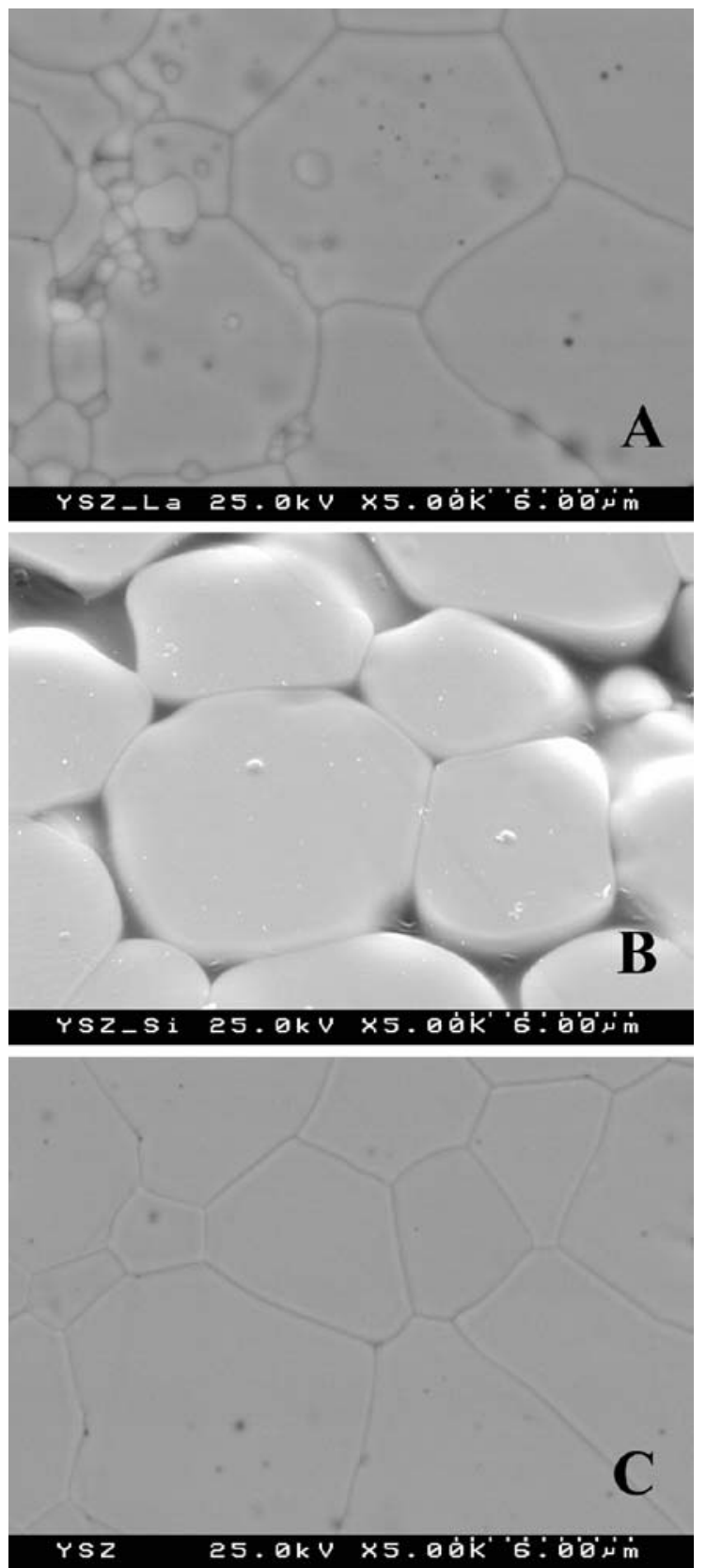

Fig. 2 Microstructure of samples (high silica content series) corresponding to the following nominal compositions: a YSZapat; b YSZsil; c YSZ. The meaning of the short designations can be found in the main text

The composite with apatite shows a broad and lightly depressed high-frequency arc, followed by a much smaller low-frequency arc, related to interfacial effects (grain boundary), considering the frequency range involved. The apparent drop in bulk conductivity (by a factor of about 2) with respect to the remaining compositions is hardly understood as a consequence of changes in the YSZ bulk composition, as already discussed based on XRD data. One likely explanation for this apparent drop in conductivity would be the formation of a thin pyrochlore layer inbetween YSZ grains, blocking the ionic transport. In fact, the conductivity of lanthanum zirconate is orders of 


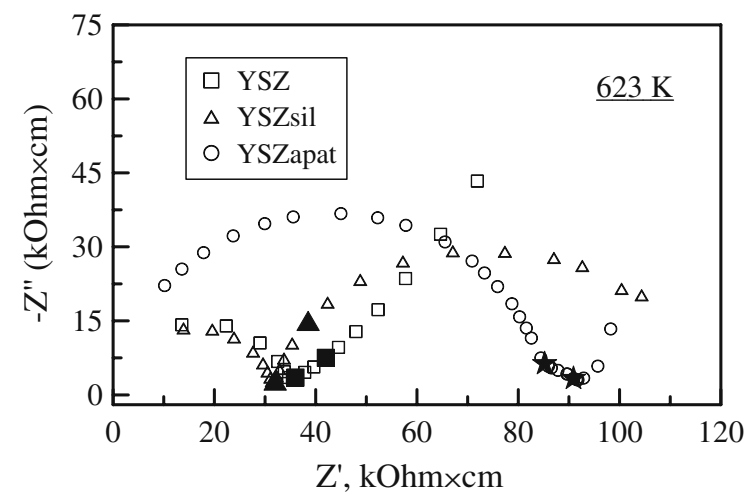

Fig. 3 Impedance plot at $623 \mathrm{~K}$, in air, of samples shown in Fig. 2. Large filled symbols correspond to data points close to 1 and $10 \mathrm{kHz}$. The meaning of the short designations can be found in the main text

magnitude lower than that of YSZ, and extremely thin layers would determine this type of response. Also, in other systems where YSZ reacts with lanthanum-containing materials (e.g., the already mentioned LSM and LSC), there is a clear tendency for the formation of continuous thin zirconate layers between the reactants, easily detected by electrical measurements, well-before being noticed by SEM or XRD.

Literature data on the conductivity of apatite-type $\mathrm{La}_{9.33} \mathrm{Si}_{6} \mathrm{O}_{26}$, which is expected to form in the composite electrolyte, are also contradictory. Tao and Irvine [17] reported relatively poor transport properties for this phase, with high cation deficiency and low concentration of interstitial oxygen; other authors observed one conductivity level comparable to YSZ [18]. In the case of significant compositional deviations, further drop in conductivity of the apatite phase may be expected. All these effects would contribute to the observed loss in conductivity.

Lastly, the small grain boundary response suggests the effectiveness of lanthanum oxide additions to clean grain boundaries by combination with silica.

Figure 4 shows the total conductivity of all samples in a typical Arrhenius-type plot. The total conductivity was obtained, as usual, after fitting experimental data to an equivalent circuit comprising two RQ elements (related to the grain and grain boundary contributions), and one additional contribution related to the electrode process. $\mathrm{R}$ and Q stand for resistance and constant phase element. Literature data on $\mathrm{La}_{9.33} \mathrm{Si}_{6} \mathrm{O}_{26}$ are presented for comparison $[17,18]$. The already discussed drop in total conductivity for composites, due to the high interfacial YSZ-silica impedance, formation of thin pyrochlore resistive layers, and/or poor transport properties of the formed silicate solid solution, prevents the use of these heavily doped materials as an alternative to pure YSZ up to typical SOFC working temperatures.

Overall, the impedance spectra together with SEM and XRD suggest that the basic idea behind the utilization of lanthanum oxide to combine with silica was effective, although the formation of lanthanum zirconate partly cancelled the positive effect of this solution.

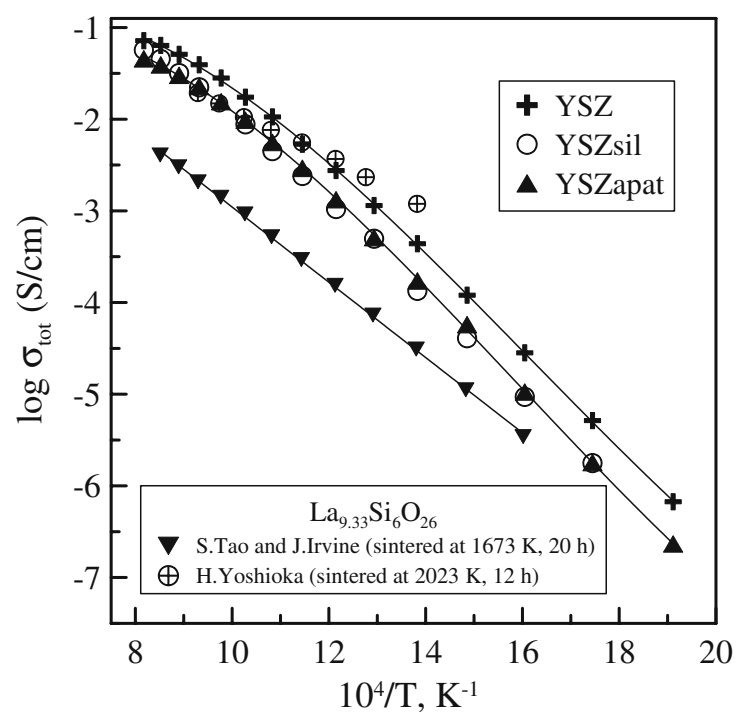

Fig. 4 Arrhenius plot of total conductivity in air, of samples shown in Fig. 2. The meaning of the short designations can be found in the main text Data on $\mathrm{La}_{9.33} \mathrm{Si}_{6} \mathrm{O}_{26}$ are shown for comparison $[17,18]$

\section{Lightly $\mathrm{SiO}_{2}$-doped samples}

The second set of samples was based on light silica additions, in the order of $0.5 \mathrm{~mol} \%$. The corresponding microstructures can be seen in Fig. 5. A fast comparison between microstructures shown in Figs. 1 and 5 is enough to highlight the need for high levels of silica additions to obtain clear microstructural effects, namely visible formation of new phases. Samples with silica and silica + alumina shown in Fig. 5 only suggest the presence of isolated spots of secondary phases along the grain boundaries and close to triple contact points between YSZ grains. The sample with silica + lanthanum oxide suggests a more diluted distribution of secondary phases. In fact, their presence is hardly noticed. No attempt was made to identify the presence and/or formation of secondary phases by XRD, considering the expected low content of these phases, and that all results should obey the tendencies already discussed for the first set of samples.

The electrical characterization of all these samples provided again additional information on phase interaction (Fig. 6). The identification of the relevant contributions is again obvious from the frequency ranges involved. Both high-frequency and low-frequency arcs correspond to equivalent phenomena irrespective of the sample composition. Bulk effects dominate at high frequency, and interfacial effects dominate in the lower frequency range. All spectra end at extreme low frequencies with vestiges of the so-called electrode response.

Single silica additions and combined silica and alumina additions provide identical performance in the entire frequency range, with a slight benefit for the material with alumina, as expected for the well-documented scavenger effect. These impedance spectra in fact suggest the typical performance of one electrolyte with modest levels of impurities and relatively clean grain boundaries. Over- 

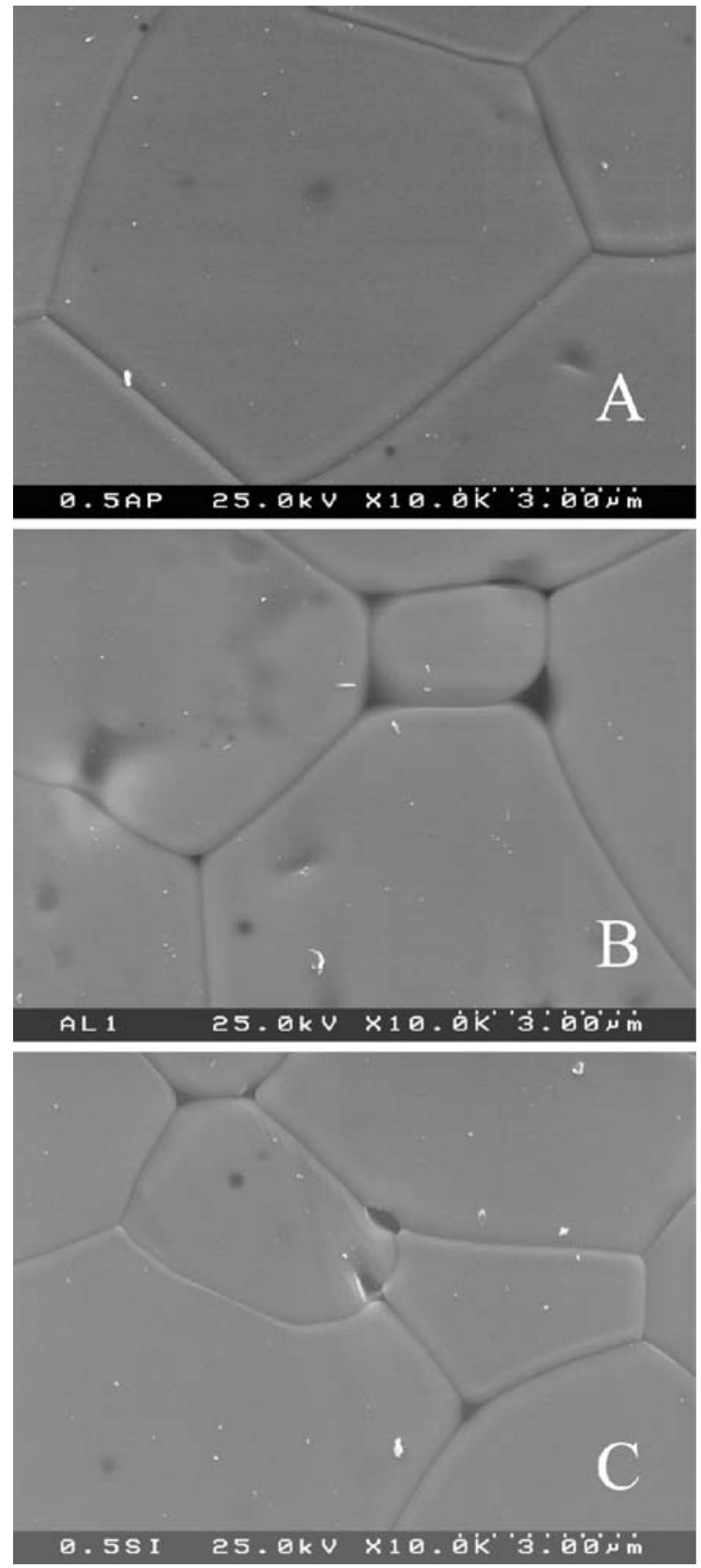

Fig. 5 Microstructure of samples (low silica content series) corresponding to the following nominal compositions: a YSZapat; b YSZalusil; c YSZsil. The meaning of the short designations can be found in the main text

all, the grain boundary arcs are more visible than for pure YSZ (shown in Fig. 3), but still within reasonable limits.

Again, the composition including the apatite phase shows a large bulk arc and a modest grain boundary arc. As observed for the samples with high silica content, the presence of a thin pyrochlore layer in-between YSZ grains should be considered to explain the presence of this relatively large high-frequency arc. Furthermore, comparison of these data with Fig. 3 shows that the bulk arcs now are within a smaller range. This is coherent with the overall smaller content in lanthanum oxide, which is responsible for the reaction with YSZ to form the zirconate phase.

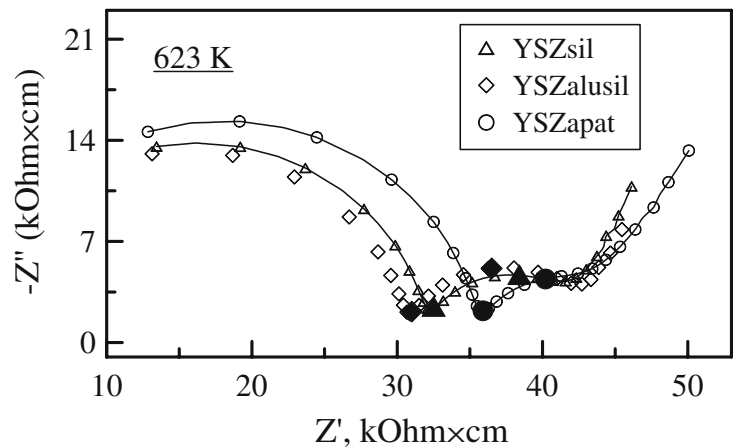

Fig. 6 Impedance plot at $623 \mathrm{~K}$, in air, of samples shown in Fig. 5. Large filled symbols correspond to data points close to 1 and $10 \mathrm{kHz}$. The meaning of the short designations can be found in the main text

\section{Final comments}

Microstructures are important in ceramics in general but, in the case of composites, microstructure-property relationships are even more relevant. The presence, formation, content, and location of secondary phases might determine a completely different set of properties with respect to a single phase material. The basic idea behind the coaddition of silica and lanthanum oxide to YSZ was the demonstration of an alternative, and more effective solution, to the scavenger effect observed in the combined presence of silica and alumina. This work fully demonstrated the effectiveness of this approach although interaction between zirconia and lanthanum oxide was found prevailing and detrimental due to formation of lanthanum zirconate. This second effect is responsible for enhanced ohmic losses with respect to pure YSZ. However, the grain boundary contribution, also present in this case, decreased significantly, showing the potential of this type of approach and opening directions for other developments.

The present results might be improved with other firing schedules (time and temperature) considering the combined role of kinetics and thermodynamics in the global result. This was not yet attempted. However, one indirect consequence of this work is the possible search for systems where phase interaction might be limited. One obvious case is testing the same approach with ceria-based electrolytes. Formation of compounds with cerium and lanthanum is unlikely. Therefore, the single effect due to formation of the apatite phase might be exploited in better circumstances in this case.

Depending on the exact location of these secondary phases in the composite materials, additional directions for research can be envisaged. As an example, electronblocking effects might be obtained if one apatite phase fully covers the ceria-based grains, as in core-shell microstructures. In fact, several apatites show modest levels of electronic conduction when compared to ceriabased electrolytes. This would be a rather interesting alternative to planar double-layer electrolyte cells conceived to control the negative role of enhanced electronic conductivity in ceria-based electrolytes at high temperature 
and under reducing conditions [31,32]. Microstructural development of novel types of composite electrolytes is thus believed to be a promising field for further research.

\section{Conclusions}

Silica and lanthanum oxide joint additions to YSZ were involved in the formation of new phases, namely one apatite (nominal composition $\mathrm{La}_{9.33} \mathrm{Si}_{6} \mathrm{O}_{26}$ ) and one pyrochlore (nominal composition $\mathrm{La}_{2} \mathrm{Zr}_{2} \mathrm{O}_{7}$ ), as suggested from combined analysis of XRD, SEM, and impedance spectroscopy data. The formation of these new phases demonstrated the potential of different combinations of materials to improve or change the base material performance in ways similar to the scavenger effect, well documented in the case of combined presence of silica and alumina. While the overall performance of the composites now studied was lower than desirable, the effectiveness of the procedure can be extended to other systems and combinations of properties.

Acknowledgement This work was partially supported by FCT, Portugal (SFRH/BPD/15003/2004).

\section{References}

1. Steele BCH, Powell BE, Moody PMR (1968) Anionic conduction in refractory oxide solid solutions possessing the fluorite, pyrochlore and perovskite structures. Proc Brit Ceram Soc 10:87-102

2. Etsell TH, Flengas SN (1970) The electrical properties of solid oxide electrolytes. Chem Rev 70:339-376

3. Cales B, Baumard JF (1983) Conduction and defect structure of $\mathrm{ZrO}_{2}-\mathrm{CeO}_{2}-\mathrm{Y}_{2} \mathrm{O}_{3}$ solid solutions. $\mathrm{J}$ Electrochem Soc $131: 2407-2413$

4. Subbarao EC, Maiti HS (1984) Solid electrolytes with oxygen ion conduction. Solid State Ionics 11:317-338

5. Skinner SJ, Kilner JA (2003) Oxygen ion conductors. Mater Today 30-37

6. Kharton VV, Marques FMB, Atkinson A (2004) Transport properties of solid oxide electrolyte ceramics: a brief review. Solid State Ionics 174:135-149

7. Ishihara T, Matsuda $\mathrm{H}$, Takita $\mathrm{Y}$ (1994) Doped $\mathrm{LaGaO}_{3}$ perovskite type oxide as a new oxide ionic conductor. J Am Chem Soc 116:3801-3803

8. Feng M, Goodenough JB (1994) A superior oxide-ion electrolyte. Eur J Solid State Inorg Chem 31:663-672

9. Huang P, Petric A (1996) Superior oxygen ion conductivity of lanthanum gallate doped with strontium and magnesium. J Electrochem Soc 143:1644-1648

10. Baker RT, Gharbage B, Marques FMB (1997) Ionic and electronic conduction in $\mathrm{Fe}$ and $\mathrm{Cr}$ doped $(\mathrm{La}, \mathrm{Sr}) \mathrm{GaO}_{3}$. J Electrochem Soc 144:3130-3135

11. Kharton VV, Viskup AP, Naumovich EN, Lapchuk NM (1997) Mixed electronic and ionic conductivity of $\mathrm{LaCo}(\mathrm{M}) \mathrm{O}_{3}$ $(\mathrm{M}=\mathrm{Ga}, \mathrm{Cr}, \mathrm{Fe}$ or $\mathrm{Ni})$ : I. Oxygen transport in perovskites $\mathrm{LaCoO}_{3}-\mathrm{LaGaO}_{3}$. Solid State Ionics 104:67-78
12. Kharton VV, Shaula AL, Vyshatko NP, Marques FMB (2003) Electron-hole transport in $\left(\mathrm{La}_{0.9} \mathrm{Sr}_{0.1}\right)_{0.98} \mathrm{Ga}_{0.8} \mathrm{Mg}_{0.2} \mathrm{O}_{3-\delta}$ electrolyte: effect of ceramic microstructure. Electrochim Acta 48:1817-1828

13. Kharton VV, Viskup AP, Kovalevsky AV, Naumovich EN, Marques FMB (2001) Ionic transport in oxygen-hyperstoichiometric phases with $\mathrm{K}_{2} \mathrm{NiF}_{4}$-type structure. Solid State Ionics $143: 337-353$

14. Bassat JM, Odier P, Villesuzanne A, Marin C, Pouchard M (2004) Anisotropic ionic transport properties in $\mathrm{La}_{2} \mathrm{NiO}_{4+\delta}$ single crystals. Solid State Ionics 167:341-347

15. Nakayama S, Kageyama T, Aono H, Sadaoka Y (1995) Ionic conductivity of lanthanoid silicates, $\mathrm{Ln}_{10}\left(\mathrm{SiO}_{4}\right)_{6} \mathrm{O}_{3}(\mathrm{Ln}=\mathrm{La}$, Nd, Sm, Gd, Dy, Y, Ho, Er and Yb). J Mater Chem 5:1801-1805

16. Nakayama S, Sakamoto M (1998) Electrical properties of new type high oxide ionic conductor $\mathrm{RE}_{10} \mathrm{Si}_{6} \mathrm{O}_{27}(\mathrm{RE}=\mathrm{La}, \mathrm{Pr}, \mathrm{Nd}$, Sm, Gd, Dy,). J Eur Ceram Soc 18:1413-1418

17. Tao S, Irvine JTS (2001) Preparation and characterization of apatite-type lanthanum silicates by a sol-gel process. Mater Res Bull 36:1245-1258

18. Yoshioka H (2004) High oxide ion conductivity in Mg-doped $\mathrm{La}_{10} \mathrm{Si}_{6} \mathrm{O}_{27}$ with apatite-type structure. Chem Lett 33:392-393

19. Sansom JEH, Richings D, Slater PR (2001) A powder neutron diffraction study of the oxide-ion-conducting apatite-type phases, $\mathrm{La}_{93}{ }_{33} \mathrm{Si}_{6} \mathrm{O}_{26}$ and $\mathrm{La}_{8} \mathrm{Sr}_{2} \mathrm{Si}_{6} \mathrm{O}_{26}$. Solid State Ionics 139:205-210

20. McFarlane J, Barth S, Swaffer M, Sansom JEH, Slater PR (2002) Synthesis and conductivities of the apatite-type systems, $\mathrm{La}_{9.33+\mathrm{x}} \mathrm{Si}_{6-\mathrm{y}} \mathrm{M}_{\mathrm{y}} \mathrm{O}_{26+\mathrm{z}}(\mathrm{M}=\mathrm{Co}, \mathrm{Fe}, \mathrm{Mn})$ and $\mathrm{La}_{8} \mathrm{Mn}_{2} \mathrm{Si}_{6} \mathrm{O}_{26}$. Ionics 8:149-154

21. Shaula AL, Kharton VV, Waerenborgh JC, Rojas DP, Tsipis EV, Vyshatko NP, Patrakeev MV, Marques FMB (2004) Transport properties and Mossbauer spectra of Fe-substituted $\mathrm{La}_{10-\mathrm{x}}(\mathrm{Si}$, Al) ${ }_{6} \mathrm{O}_{26}$ apatites. Mater Res Bull 39:763-773

22. Tolchard JR, Islam MS, Slater PR (2003) Defect chemistry and oxygen ion migration in the apatite-type materials $\mathrm{La}_{9.33} \mathrm{Si}_{6} \mathrm{O}_{26}$ and $\mathrm{La}_{8} \mathrm{Sr}_{2} \mathrm{Si}_{6} \mathrm{O}_{26}$. J Mater Chem 13:1956-1961

23. Kharton VV, Shaula AL, Patrakeev MV, Waerenborgh JC, Rojas DP, Vyshatko NP, Tsipis EV, Yaremchenko AA, Marques FMB (2004) Oxygen ionic and electronic transport in apatitetype solid electrolytes. J Electrochem Soc 151:A1236-A1246

24. Shaula AL, Kharton VV, Marques FMB (2005) Oxygen ionic and electronic transport in apatite-type $\mathrm{La}_{10-x}(\mathrm{Si}, \mathrm{Al})_{6} \mathrm{O}_{26 \pm \delta}$. J Solid State Chem 178:2050-2061

25. Shaula AL, Kharton VV, Waerenborgh JC, Rojas DP, Marques FMB (2005) Oxygen ionic and electronic transport in apatite ceramics. J Eur Ceram Soc 25:2583-2586

26. Butler EP, Drennan J (1982) Microstructural analysis of sintered high-conductivity zirconia with $\mathrm{Al}_{2} \mathrm{O}_{3}$ additions. J Am Ceram Soc 65(10):474-478

27. Labrincha JA, Frade JR, Marques FMB (1997) Protonic conduction in $\mathrm{la}_{2} \mathrm{Zr}_{2} \mathrm{O}_{7}$-based pyrochlore materials. Solid State Ionics 99:33-40

28. Labrincha JA, Marques FMB, Frade JR (1993) $\mathrm{La}_{2} \mathrm{Zr}_{2} \mathrm{O}_{7}$ formed at ceramic electrode/YSZ contacts. J Mater Sci 28:3809-3815

29. Rodrigues CMS, Labrincha JA, Marques FMB (1997) Study of YSZ-glass composites by impedance spectroscopy. J Electrochem Soc 144(12):4303-4309

30. Rodrigues CMS, Labrincha JA, Marques FMB (1998) Monitoring of the corrosion of YSZ by impedance spectroscopy. J Eur Ceram Soc 18:95-104

31. Marques FMB, Navarro LM (1996) Performance of double layer electrolyte cells. Part I: model behavior. Solid State Ionics 90:183-192

32. Marques FMB, Navarro LM (1997) Performance of double layer electrolyte cells. Part II: GCO/YSZ - a case study. Solid State Ionics 100:29-38 